\title{
Cell Population of Mesenchymal Stem Cells on Micro-patterned Titanium
}

\author{
Mariko Kawai $^{1}$, Noriyuki Nagaoka ${ }^{2}$, Yasuhiro Yoshida ${ }^{3}$, Kiyoshi Ohura ${ }^{1}$ \\ ${ }^{1}$ Department of Pharmacology, Osaka Dental University \\ 8-1 Kuzuhahanazono-cho, Hirakata city, Osaka, Japan \\ kawai-m@cc.osaka-dent.ac.jp; ohura @cc.osaka-dent.ac.jp \\ ${ }^{2}$ Graduate School of Medicine, Dentistry and Pharmaceutical Sciences, Okayama University \\ 2-5-1 Shikata-cho, Okayama city, Japan \\ nagaoka@okayama-u.ac.jp \\ ${ }^{3}$ Biomaterials and Bioengineering, Graduate School of Dental Medicine, Hokkaido University \\ Kita 13, Nishi 7, Sapporo city, Japan \\ yasuhiro@den.hokudai.ac.jp
}

\begin{abstract}
Dental implants are highly effective for improving the occlusion function after tooth loss. However, ordinarily titanium dental implants sometimes require long term for the osseointegration. If there is insufficient bone in the patients, surgical pre-treatment such as autologous bone transplantation is required, imposing a big burden on the patient. Furthermore, a predominance of invasion of the gingival epithelium by epithelial cells at an early stage increases the risk of unsuccessful osseointegration. Therefore, to reduce the burden on the patient and increase the success rate of dental implant treatment, we need to develop a dental implant that can promote osseointegration more quickly and efficiently. We presumed that it would be one of efficient strategies for the quick and reliable osseointegration if we could control the cell population around the dental implant. Here, we micro-patterned a titanium surface by using a gelatin matrix. Mesenchymal stem cells were cultured, and cell populations were investigated. On the titanium surface with a micro-patterned gelatin matrix, mesenchymal stem cells first adhered to the titanium and then to the gelatin, enabling cell adhesion to be controlled time dependently. These results suggest that it may be possible to develop functional dental implants in which we can control the cell population of epithelial and mesenchymal stem cells and can promote quick and reliable osseointegration.
\end{abstract}

Keywords: dental implant, titanium, micro-pattern, gelatin, cell population, osseointegration

\section{Introduction}

Dental implants are very effective treatment for ecovering the occlusion after tooth loss $[1,2,3]$. However, in general, it takes long term for the osseointegration, it means the direct structural and functional connection between bone and the surface of the titanium of dental implants $[4,5]$. If there is insufficient bone, surgical pre-treatment such as autologous bone transplantation is required, imposing a big burden on the patient. Furthermore, a predominance of invasion of the gingival epithelium by epithelial cells at an early stage increases the risk of unsuccessful osseointegration. Therefore, to reduce the burden on the patient and increase the success rate of dental implant treatment, we need to develop a dental implant that can promote quick and reliable osseointegration. We presumed that it would be one of efficient strategies for the quick and ensure osseointegration of the dental implant if we could control the cell population on the surface of titanium of the dental implant.

In this study, we aimed to control the cell population of mesenchymal stem cells on a titanium surface.

\section{Materials and Methods}

\subsection{Micro-patterning of gelatin matrix on titanium surface}

A photomask was positioned with the light-shield film-side facing upwards (Fig. 1a). Photo-setting resin was then dripped on to the slits of the photomask (Fig.1b). After the photomask had been covered with a base film (Fig.1c), UV 
radiation was applied above the base film to harden the photo-setting resin in contact with the film (Fig.1d). The photomask was then flipped upside down, and UV radiation was applied through the slits of the photomask (Fig.1e). The base film was detached from the photomask (Fig.1f), and any unhardened resin was washed off by using a cleaning solution (Fig.1g). UV radiation was then applied with the film in water and the resin side upward. The film was removed from the water and dried (Fig.1h).

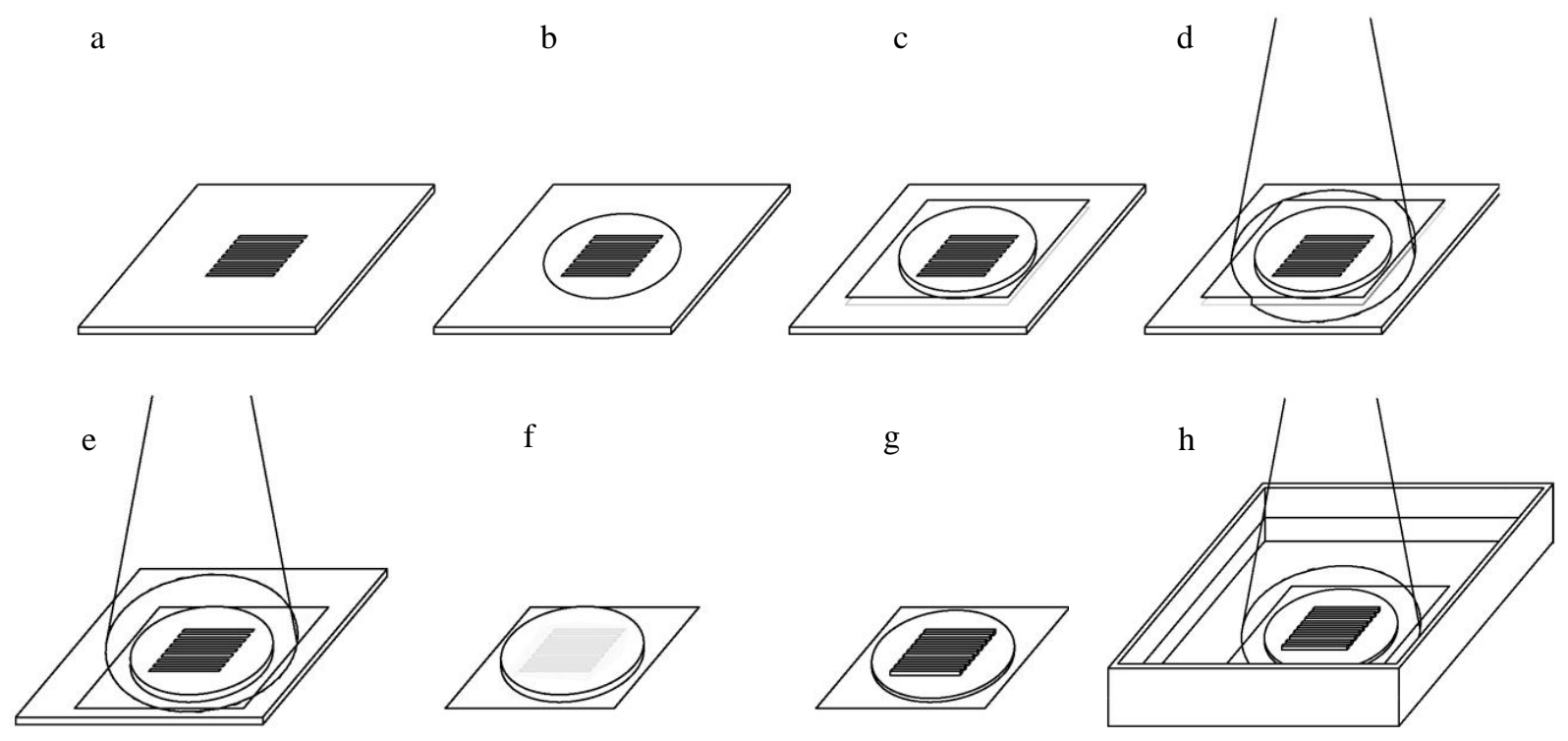

Fig. 1: Fixing gelatin matrix to the titanium plate.

\subsection{Cell culture on titanium surface with micro-patterning of gelatin matrix}

Cell culture on titanium surface with micro-patterning of gelatin matrix was performed as below. As mesenchymal stem cells, cells of the mouse 10T1/2 cell line (RIKEN cell bank, Japan) were cultured on micro-patterned titanium plates placed on a 24 -well plate, starting at $1 \times 10^{5}$ cells per well. The cells were cultured at $37{ }^{\circ} \mathrm{C}$ under a $5 \% \mathrm{CO}_{2}$ in $\mathrm{DMEM}$ medium containing $0.5 \%$ bovine fetal serum.

\subsection{Observation of cell movements on titanium surface with a micro-patterned gelatin matrix}

Cell adhesion and movement of 10T1/2 cells on the titanium plates were observed under a phase-contrast microscope in the time laps. To observe cell time laps migration in detail, $1 \times 10^{4} 10 \mathrm{~T} 1 / 2$ cells were incubated on to the titanium plate with the micro-patterned gelatin matrix, and microscopic time laps observation was then performed. To observe cell movement during the early stages, before cell adhesion, time laps observation was started in the chamber immediately after incubation and continued for $12 \mathrm{~h}$. To observe cell movement after cell adhesion, the cells were incubated for $2 \mathrm{~h}$ after incubation and were thereafter observed under a microscope until $36 \mathrm{~h}$ after incubation.

\section{Results}

\subsection{Micro-patterning of gelatin matrix on titanium surface, and cell population of mesenchymal stem cells}

On the titanium plates with a micro-patterned gelatin matrix, 10T1/2 cells, mesenchymal stem cell line, we scattered uniformly over the surface at $0 \mathrm{~h}$ (before incubation) (Fig. 2a). However, $1 \mathrm{~h}$ after incubation, almost no cells were found adhering to the gelatin matrix sections $(100 \mu \mathrm{m})$, whereas a large number of cells adhered to the titanium sections (200 $\mu \mathrm{m}$ ), forming a pattern (Fig. 2b). At $2 \mathrm{~h}$, cell proliferation was observed but the pattern was maintained (Fig. 2c). Five hours after incubation, as the cells continued to proliferate on the titanium sections, cells also started to be observed on the gelatin matrix sections (Fig. 2d). Twenty-four hours after incubation, large numbers of cells were observed on the gelatin matrix sections and on the titanium (Fig. 2e). After $36 \mathrm{~h}$, the bridge-shaped cell proliferation on the titanium sections had 
expanded and covered the gelatin matrix sections; further cell proliferation was observed on the gelatin matrix sections (Fig. 2f).

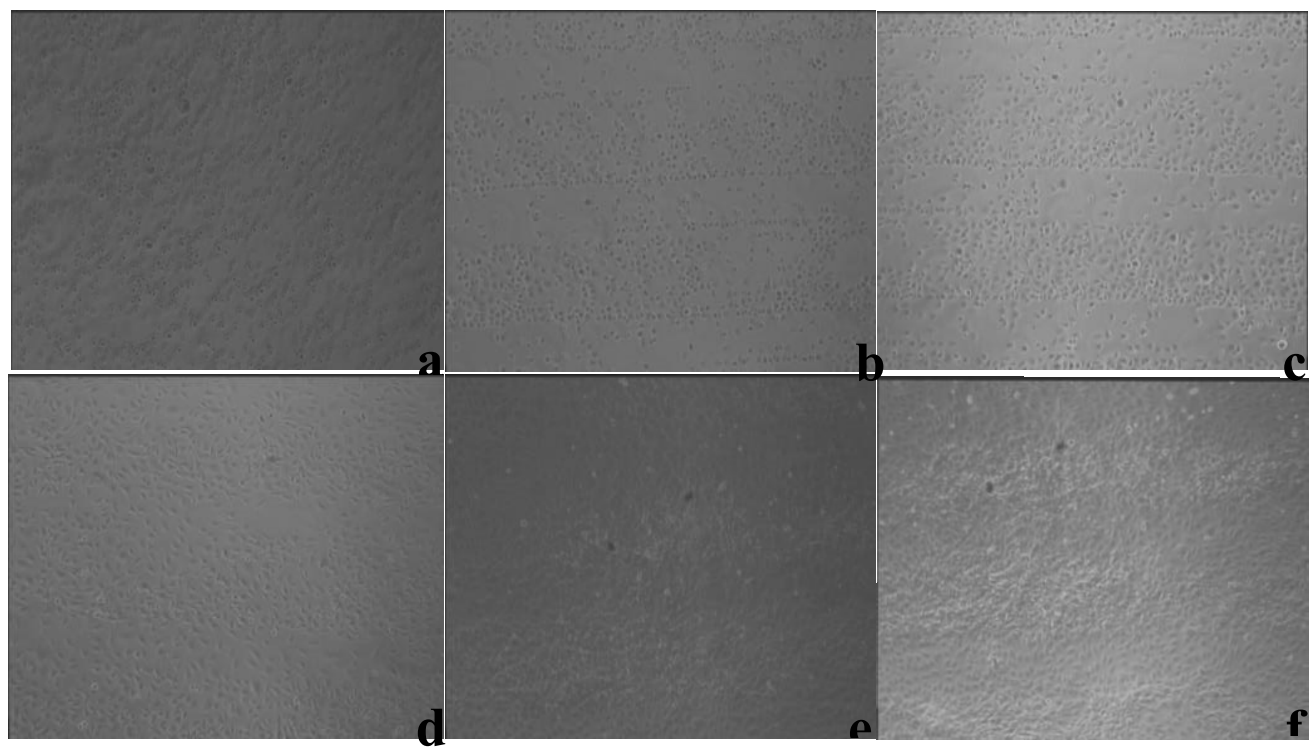

Fig. 2: Cell population of $10 \mathrm{~T} 1 / 2$ cells on the micro-pattering titanium.

\subsection{Microscopic observation of early-stage cell movement and morphology on titanium with micro- patterning}

Immediately after incubation, before the 10T1/2 cells had adhered to the surface, they were almost round (Fig. 3a, arrows). Twenty minutes after incubation, we observed that some cells migrated (Fig. 3b, arrows). Forty minutes after incubation, some cells still migrated (Fig.3c arrows). One hour after incubation, cells that had started to adhere changed their shape from round to rectangular by forming filopodia (Fig. 3d, arrows).
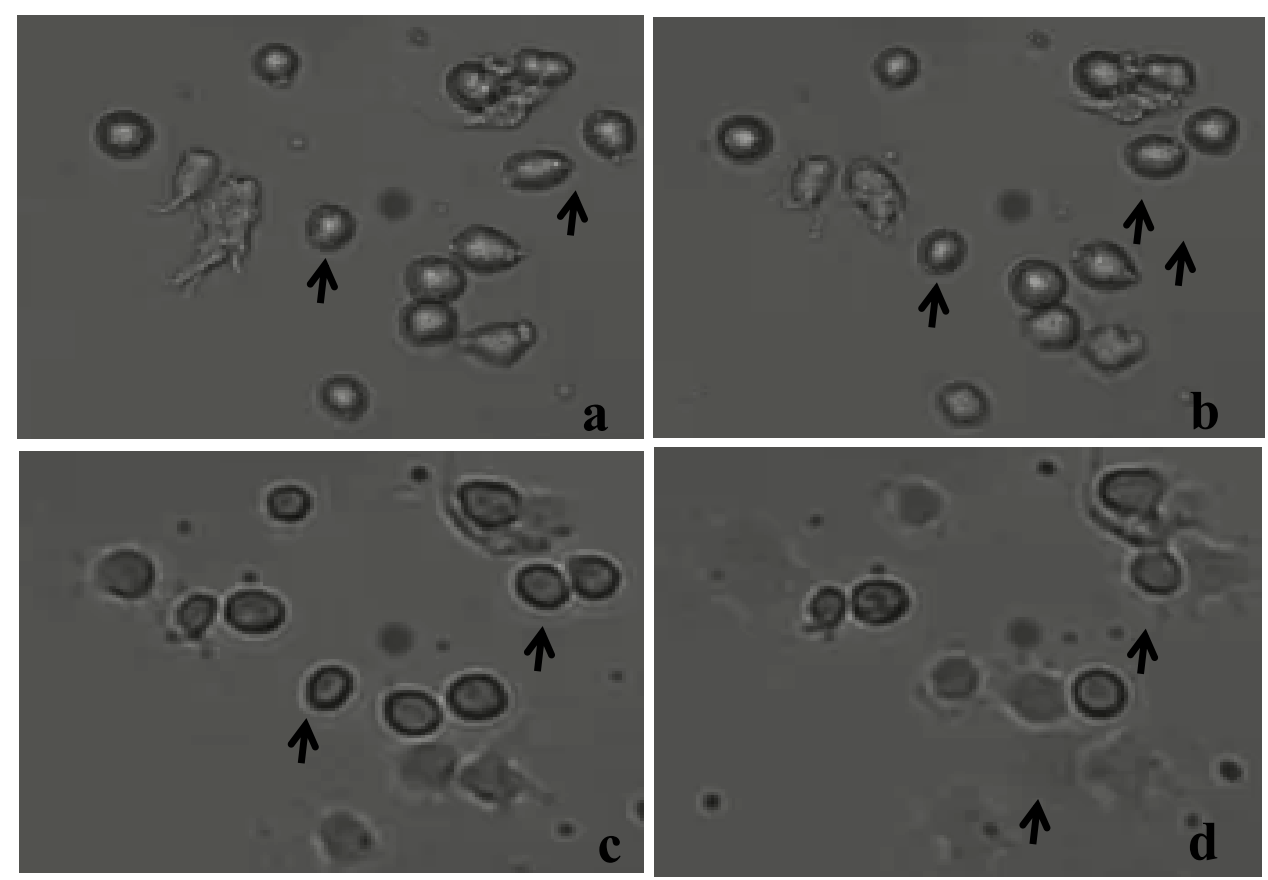

Fig. 3: Early stage cell population in titanium surface with micro-pattered gelatin matrix. 


\section{Discussion}

We analyzed the cell population of mesenchymal stem cells on titanium plates with a micro-patterned gelatin matrix. 10T1/2 cells, which are an established line with the characteristics of mesenchymal stem cells, adhered more to the titanium sections than to the gelatin matrix sections, resulting in pattern formation. The pattern, which was formed by differences in cell adhesion between the titanium and gel matrix sections, was observed within $1 \mathrm{~h}$ after cell incubation and suggested that 10T1/2 cells adhered more easily to the titanium than to the gelatin. However, our finding that, after $24 \mathrm{~h}$, the cells were also adhering to the gelatin matrix suggested that it is possible to control the adhesion of mesenchymal stem cells time dependently by using the gelatin matrix on the surface of titanium.

In dental implant treatment, prompt and reliable osseointegration is the key to success $[4,5]$. Dominant adhesion of epithelial cells instead of mesenchymal stem cells leads to failure of osseointegration. $[6,7,8,9]$. Therefore, controlling the population of epithelial and mesenchymal stem cells such that mesenchymal stem cells predominate is likely to be effective in ensuring osseointegration. As far, many researchers have developed surface modifications as sandblasting and acid etching (SLA), hydrothermal hot pressing, laser pulse, dip coating, spray plasma coating [10, 11, 12, 13, 14, 15,16, 17, $18,19]$. But, it has not yet developed that the functional dental implants can regulate the cell population.

In future studies, we plan to analyze the population of epithelial cells on titanium plates with a micro-patterned gelatin matrix. We will compare the population of these cells with those of mesenchymal stem cells and will investigate the patterns in the co-culture system of epithelial and mesenchymal stem cells on titanium plates with the aim of constructing a system for controlling the cell population of these two cell types onto the titanium surface.

\section{Conclusion}

For clinical application, we aim to develop a dental implant that prompt and reliable osseointegration by suppressing the invasion of epithelial cells onto the titanium surface while promoting the cell population of mesenchymal stem cells. This will be achieved by applying gelatin matrix at the border of the substructure and superstructure to suppress the invasion of epithelial cells from the gingival epithelium and their adhesion to the implant titanium surface.

\section{Acknowledgements}

This study was supported in part by the $25^{\text {th }}$ Grant of Suzuken Memorial Foundation.

\section{References}

[1] C. E. Misch, Contemporary Implant Dentistry, St. Louis, Missouri: Elsevier, 2007.

[2] B. E. Pjetursson, D. Thoma, R. Jung, M. Zwahlen, A. Zembic, "A systematic review of the survival and complication rates of implant-supported fixed dental prostheses (FDPs) after a mean observation period of at least 5 years," Clinical Oral Implants Research, vol. 23, pp. 22-38, 2012.

[3] D. P. Sinn, E. Bedrossian, A. K. Vest, V. Bedrossian, "Craniofacial Implant Surgery," Oral and Maxillofacial Surgery Clinics of North America., vol. 23, no. 2, pp. 321-335, 2011.

[4] J. Asbjorn, Osseointegration and Dental Implants, New York: John Wiley \& Sons, 2009.

[5] G. A. Zarb, A. Schmitt, "The longitudinal clinical effectiveness of osseointegrated dental implants: the Toronto Study. Part II: The prosthetic results," The Journal of Prosthetic Dentistry., vol. 64, no. 1, pp. 53-61, 1990.

[6] P. I. Brånemark, P. Worthington, "Advanced osseointegration surgery: applications in the maxillofacial region," Carol Stream, Illinois: Quintessence Books, 1992.

[7] M. Esposito, M. G. Grusovin, H. Maghaireh, H. V. Worthington, "Interventions for replacing missing teeth: Different times for loading dental implants," The Cochrane database of systematic reviews, vol. 3, 2013.

[8] P. Papaspyridakos, C. J. Chen, M. Singh, H. P. Weber, G. O. Gallucci, "Success Criteria in Implant Dentistry: A Systematic Review," Journal of Dental Research., vol. 91, no. 3, pp. 242-248, 2011.

[9] F. Javed, G. E. Romanos, "The role of primary stability for successful immediate loading of dental implants. A literature review," Journal of Dentistry, vol. 38, no. 8, pp. 612-620, 2010.

[10] C. A. Simmons, N. Valiquette, R. M. Pilliar, "Osseointegration of sintered porous-surfaced and plasma spray-coated implants: an animal model study of early postimplantation healing response and mechanical stability," Journal of Biomedical Materials Research, vol. 47, no. 2, pp. 127-138, 1999. 
[11] C. Knabe, F. Klar, R. Fitzner, R. J. Radlanski, and U. Gross, "In vitro investigation of titanium and hydroxyapatite dental implant surfaces using a rat bone marrow stromal cell culture system," Biomaterials, vol. 23, no. 15, pp. 3235-3245, 2002.

[12] G. L. Darimont, R. Cloots, E. Heinen, L. Seidel, and R. Legrand, "In vivo behaviour of hydroxyapatite coatings on titanium im- plants: a quantitative study in the rabbit," Biomaterials, vol. 23, no. 12, pp. 2569-2575, 2002.

[13] Y. Xie, X. Liu, X. Zheng, C. Ding, P. K. Chu, "Improvedsta-bility of plasma-sprayed dicalcium silicate/zirconia composite coating," Thin Solid Films, vol. 515, no. 3, pp. 1214-1218, 2006.

[14] S. Ban, Y. Iwaya, H. Kono, and H. Sato, "Surface modification of titanium by etching in concentrated sulfuric acid," Dental Materials, vol. 22, no. 12, pp. 1115-1120, 2006.

[15] R. Depprich, M. Ommerborn, H. Zipprich et al., "Behavior of osteoblastic cells cultured on titanium and structured zirconia surfaces," Head \& Face Medicine, vol. 4, no. 1, article 29, 2008.

[16] E. Velasco Ortega, A. Jos, A. M. Camean, J. Pato-Mourelo, J. J. Segura Egea, "In vitro evaluation of cytotoxicity and genotoxicity of a commercial titanium alloy for dental implantology," Mutation Research-Genetic Toxicology and Environmental Mutagenesis, vol. 702, no. 1, pp. 17-23, 2010.

[17] C. Aparicio, A. Padros, F. J. Gil, "In vivo evaluation of micro-rough and bioactive titanium dental implants using his-tometry and pull-out tests," Journal of the Mechanical Behavior of Biomedical Materials, vol. 4, no. 8, pp. 16721682, 2011.

[18] T. G. Eom, G. R. Jeon, C. M. Jeong et al., "Experimental study of bone response to hydroxyapatite coating implants: bone- implant contact and removal torque test," Oral Surgery, Oral Medicine, Oral Pathology and Oral Radiology, vol. 114, no. 4, pp. 411-418, 2012.

[19] K. Y. Hung, S. C. Lo, C. S. Shih, Y. C. Yang, H. P. Feng, Y. C. Lin, "Titanium surface modified by hydroxyapatite coating for dental implants," Surface and Coatings Technology, vol. 231, pp. 337-345, 2013.

[20] A. Jemet, M. J. Ghazali, M. Razali, Y. Otsuka, "Surface modification and their effects on Titanium dental implats," BioMed research International, vol. 2015, pp. 1-11, [Online] Available: http://dx.doi.org/10.1155/2015/791725, 2015. 